\title{
Determining Limits of Detection from Energy Dispersive X-ray Spectra
}

\author{
Dale E. Newbury and Robert L. Myklebust (ret.)
}

National Institute of Standards and Technology, Gaithersburg, MD 20899-8371

When comprehensive quantitative electron-excited $\mathrm{x}$-ray microanalysis is performed, the analyst is often required to specify the limits of detection (appropriate to the particular analytical conditions chosen, e.g., x-ray peak, electron dose, spectrometer resolution and efficiency, etc.) for selected elemental species of interest that might be expected to be present as trace constituents.[1] If a multi-element standard is available that is similar in composition to the unknown and that contains the constituent(s) of interest at a low but measurable level (e.g., as a minor constituent where the concentration is $0.01 \leq \mathrm{C} \leq 0.1$ mass fraction), the minimum detectable concentration, $\mathrm{C}_{\mathrm{DL}}$, can be readily estimated for the unknown. In such a dilute system, the calibration curve of k-value (where $\mathrm{k}=$ intensity of element " $\mathrm{A}$ " in the specimen/intensity of A in a pure A standard) vs. concentration is a linear function. That is, the element of interest is already so dilute that the major constituents control the matrix factors, atomic number $(\mathrm{Z})$, absorption $(\mathrm{A})$ and fluorescence $(\mathrm{F})$, thus giving a constant value of the slope, a, in the Ziebold-Ogilvie expression relating the k-value and concentration, $\mathrm{C}:[2]$

$$
(1-\mathrm{k}) / \mathrm{k}=\mathrm{a}(1-\mathrm{C}) / \mathrm{C}
$$

The relationship between the concentration limit of detection, $\mathrm{C}_{\mathrm{DL}}$, and the number of peak $\mathrm{N}_{\mathrm{P}}$ and background $\mathrm{N}_{\mathrm{B}}$ counts in the spectrum compared to these values for the measured minor concentration $\mathrm{C}_{\mathrm{M}}$, is then:

$$
\mathrm{C}_{\mathrm{DL}}=\mathrm{C}_{\mathrm{M}}\left[\left(\mathrm{N}_{\mathrm{P}}-\mathrm{N}_{\mathrm{B}}\right)_{\mathrm{DL}} /\left(\mathrm{N}_{\mathrm{P}}-\mathrm{N}_{\mathrm{B}}\right)_{\mathrm{M}}\right]
$$

It is typical practice to define $\mathrm{C}_{\mathrm{DL}}$ where the difference between the detectable peak and background is three times the standard deviation of the specimen background counts: $\left(\mathrm{N}_{\mathrm{P}}-\mathrm{N}_{\mathrm{B}}\right)_{\mathrm{DL}}=3 \mathrm{~N}_{\mathrm{B}}{ }^{1 / 2}$.

However, for most situations, a microhomogeneous standard similar in composition to the unknown and with the desired elements present at a minor level will not be available. The following procedure can be used in this more general case when energy dispersive $\mathrm{x}$-ray spectrometry is employed. The background $\mathrm{N}_{\mathrm{B}, \mathrm{DL}}$ within the energy window that defines the peak integral for a trace element is first determined, and the k-value corresponding to the detection limit is calculated:

$$
\mathrm{k}_{\mathrm{DL}}=3 \mathrm{~N}_{\mathrm{B}, \mathrm{DL}}^{1 / 2} / \mathrm{N}_{\mathrm{S}}
$$

where $N_{S}=N_{P, S}-N_{B, S}$ is the pure element standard intensity, corrected for background. The corresponding $\mathrm{C}_{\mathrm{DL}}$ is then found with the appropriate ZAF matrix correction factors for the trace element(s) of interest calculated as part of the analytical procedure:

$$
\mathrm{C}_{\mathrm{DL}}=\mathrm{k}_{\mathrm{DL}}(\mathrm{ZAF})_{\mathrm{i}}
$$

Thus, during the initialization of the analysis, the elements are selected for which the limit of detection is to be determined, and their pure element standard intensities are supplied from the database. The analytical program then measures $\mathrm{N}_{\mathrm{B}, \mathrm{DL}}$ for those elements, determines $\mathrm{k}_{\mathrm{DL}}$ with equation (3), and calculates $\mathrm{C}_{\mathrm{DL}}$ with equation (4). This procedure is illustrated in Figure 1 as implemented within NIST-NIH Desktop Spectrum Analyzer (DTSA). The specimen of interest for the analysis is NIST glass K411 (Standard Reference Material 470), which contains O, Mg, Si, Ca, and $\mathrm{Fe}$. The elements/peaks selected for the $\mathrm{C}_{\mathrm{DL}}$ calculation, whose corresponding windows are highlighted in Figure 1, include $\mathrm{VK} \alpha, \mathrm{TaL} \alpha$, and $\mathrm{PbM} \alpha$. The analytical procedure recovers the background intensity in these windows from the spectrum of the unknown, and the pure element 
standard intensity from the appropriate standard. Using the ZAF factors calculated for each dilute element, $\mathrm{C}_{\mathrm{DL}}$ is calculated with equation (4). The $\mathrm{C}_{\mathrm{DL}}$ results for a typical accumulation time (100s at $\sim 30 \%$ deadtime) and for a long accumulation (3000s at 30\% deadtime) are listed in Table 1 . This $\mathrm{C}_{\mathrm{DL}}$ software tool is incorporated in the ZAF quantitative analysis procedure embedded in DTSA.[3]

When the element of interest for the $\mathrm{C}_{\mathrm{DL}}$ calculation suffers interference from a nearby peak of a major or minor constituent, the problem becomes more difficult. For the interference case, the spectrum simulation capabilities of DTSA can be used to artificially add a known level of a trace component to the region of interest, followed by peak fitting studies of the composite peak to determine the statistical limits of the procedure to recover the trace intensity.[3]

\section{References}

[1] J.I. Goldstein et al., Scanning Electron Microcopy and X-ray Microanalysis, $3^{\text {rd }}$ ed. (Kluwer Academic Plenum, New York, 2003) 446.

[2] T.O. Ziebold and R.E. Ogilvie, Anal. Chem. 36 (1964) 222.

[3] Desktop Spectrum Analyzer, C. Fiori, C. Swyt, and R. Myklebust (1991); public domain software available from the National Institute of Standards and Technology website:

http://www.cstl.nist.gov/div837/Division/outputs/DTSA/DTSA.htm

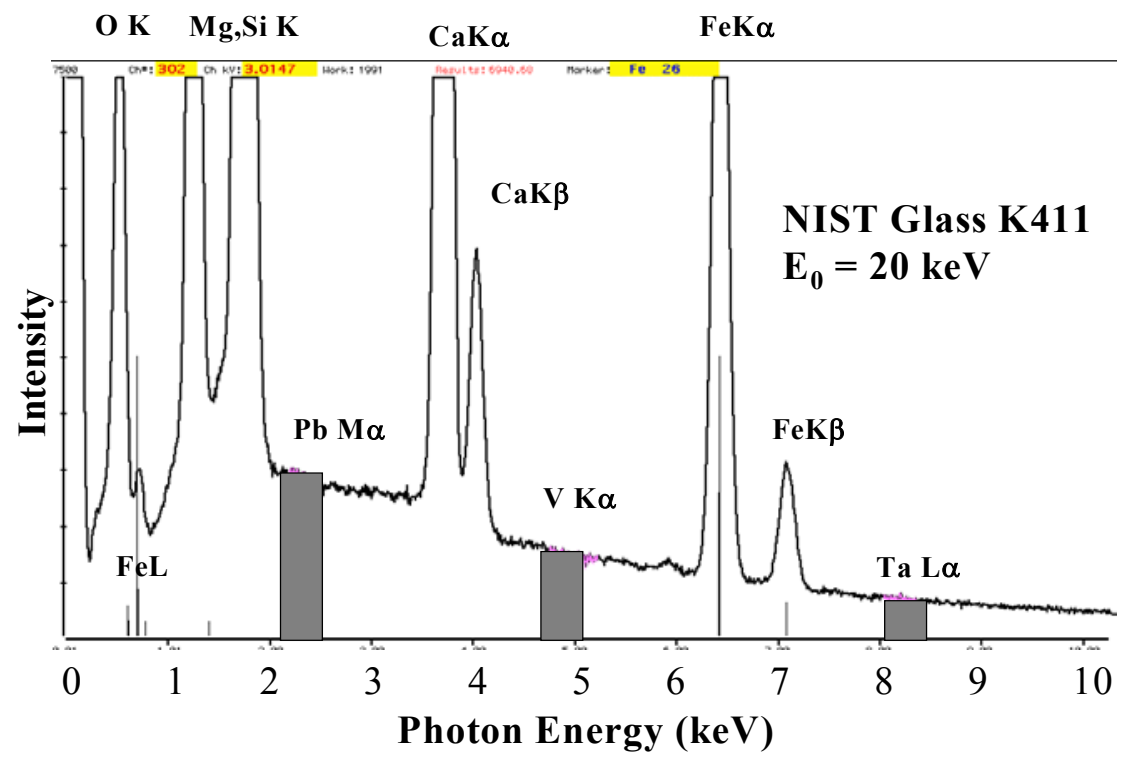

Table 1 Concentration Limit of Detection in NIST Glass K411 ( $30 \%$ deadtime)

100 s livetime

$\mathrm{PbM} \alpha$

$\mathrm{V} \mathrm{K} \alpha$

TaL $\alpha$
0.00217 mass fraction

0.000843

0.00467
$3000 \mathrm{~s}$ livetime

0.000391 mass fraction

0.000153

0.000865 